\title{
On the Raison D'être of the Present Perfect, with Special Reference to the English Grammeme
}

\author{
By Krasimir Kabakciev ${ }^{*}$
}

The present perfect is a mystery and most linguists agree that its definitions are inadequate. The paper deals with two major issues: (i) what is its second meaning, beside the temporal one; (ii) what is its raison d'etre? Is it the expression of notions such as current relevance or resultativeness? The analysis is based on recent findings that the present perfect performs a grammaticalizing function with certain sentences belonging to a semantico-syntactic schema in two languages, Bulgarian and Montenegrin. It shows that, as regards (i), the present perfect is a form that can be termed non-witnessed in itself in Bulgarian and English. However, while in English and Montenegrin it is not grammatically marked as non-witnessed (in Bulgarian it is), in English and Bulgarian it signals this value - but not by default. Conversely, the indefinite past in English, to which the present perfect is invariably contrasted, is a witnessed form by default, hence its witnessed value can be canceled in a sentence/context. In other words, the English indefinite past is not grammatically marked as witnessed and does not signify this value - but signals it by default. As regards (ii), the raison d'être of the English present perfect is argued to be the signaling (not by default) of the value non-witnessed to counterbalance the default value witnessed in the indefinite past. Bottom line: the raison d'être of the present perfect across languages appears to be found not in its "meaning" but in certain functions related to language structure that it performs.

Keywords: present perfect; indefinite past; (non-)witnessed; (non-)cancelable; residual function.

\section{Introduction}

The analysis in this paper rests on a recent finding that the present perfect in Bulgarian exercises the function of "grammaticalizing" certain types of sentences - ill- formed and belonging to a particular semantico-syntactic schema (Kabakčiev 2018). The present perfect and perfects in general are found in many European and other languages but there are also languages without perfects (Comrie 1985, Bybee et al. 1994: 54, 61, Dahl 1985: 129ff, Aikhenvald 2004: 28); the abovementioned schema, represented by clauses such as $X$ said that and adverbials such as according to, probably, etc., is widely found across languages (Aikhenvald 2008, Spronck and Nikitina 2019) ${ }^{1}$ and prevalent in all modern ones, including English. To demonstrate the grammaticalizing function, compare Bulgarian (1a-b)

\footnotetext{
*Independent Researcher, Bulgaria.

${ }^{1}$ Aikhenvald (2008: 384): "every language has some way of reporting what someone has said".
} 
- incorrect sentences with witnessed forms, and their grammatical correspondences (2a-b) with present perfect forms, non-witnessed:
a. *Petar kaza, che Maria pristigna ${ }_{\text {wIT }}$ 'Peter said that Maria arrived'
b. *Spored Petar Maria pristigna ${ }_{\mathrm{wITN}}$ 'According to Peter, Maria arrived'
a. Petar kaza, che Maria e pristignala $a_{\text {PERFECT }}$
(lit.) 'Peter said that Maria has arrived'
b. Spored Petar Maria e pristignala $a_{\text {PERFECT }}$
'According to Peter, Maria has arrived'

The non-grammaticality is due to the incompatibility between witnessed and non-cancelable forms, on the one hand, and phrases/clauses such as according to, $X$ said that, etc., on the other. ${ }^{2}$ The latter require all expressions associated with them to be cancelable ${ }^{3}$ (either true or not true, such that either materialized or not, etc.), and if the associated expressions are non-cancelable, and witnessed in particular like those in (1), they are incompatible. Obviously, non-grammaticality cannot be "tolerated", so present perfect forms (that are non-witnessed) are used in (2) to obtain grammaticality. ${ }^{4}$ The perfect in (2) has renarrative or inferrential meaning, or both, it is non-witnessed (always) and cancelable in the schema.

This elimination of non-grammaticality is a very important finding because it provides irrefutable proof of an existence of a function exercised by the present perfect related to language structure - something never previously established in linguistics. ${ }^{5}$ Most probably it is a step in the right direction for determining the reason(s) why the perfect exists in certain languages and not in others. What is more, the finding has been shown to be valid for another language - the Montenegrin present perfect also "grammaticalizes" incorrect sentences with witnessed forms (aorist or imperfect), see Bulatović (2018):
a. *Džon reče Aor/Pf/Dož da stiže $\mathrm{Aor} / \mathrm{P} / \mathrm{Dož}$ 'John said that he arrived'
b. Džon reče Aor/Pf/Dož $_{\text {da je stigao }}$ Perf/Pf
(lit.) 'John said that he has arrived' ${ }^{6}$

Note, however, that the Montenegrin present perfect is, in essence, a preterite. Yet this preterite is formed as a perfect - from the past active participle of the main

\footnotetext{
${ }^{2}$ In this paper, the standard understanding of grammaticality/non-grammaticality (correctness/ incorrectness of language expressions) is followed, as known since the beginning of modern linguistics: the fundamental aim of linguistic analysis is to separate grammatical sequences from ungrammatical ones (Chomsky 1957: 13). In the sentences analyzed here the task is easy: nongrammaticality (incorrectness) is not subject to doubt.

${ }^{3}$ Cancelable and non-cancelable are well-established concepts after Grice's (1975) pioneering work.

${ }^{4}$ Grammaticalization can also be achieved by renarrative mood forms (pristignala 'arrived').

${ }^{5}$ To the author's knowledge.

${ }^{6}$ Instead of Serbo-Croatian, today Serbian, Croatian, Montenegrin and Bosnian are officially recognized languages, so the regularity is actually valid for four languages, not just one.
} 
verb plus the present tense of the auxiliary be, in contrast to the preterite in other Slavic languages (Czech, Polish, Russian), where it is a single verb.

The grammaticalizing function of the present perfect in Bulgarian and Montenegrin ought to be accompanied by an explanation of the essence of the perfect, its raison d'être. But actually this is the main aim of this work - and it is a difficult one. The present perfect has never been given a convincing explanation and is regularly described as a puzzle (Klein 1992, Pancheva and von Stechow 2004, Higginbotham 2009: 160). The circumstance that in English it excludes adverbials of past time only adds to its mystery; most other languages do not manifest this feature. Furthermore, many errors have been made in the description of tense and aspect in studies of the English tense system (see Kabakčiev 2000: 1, 157) and especially in English grammars (see Bulatović 2013, 2020). Tense has almost invariably been defined as "locating a situation in time"7 (Comrie 1985: 9, Huddleston and Pullum 2002: 116, Declerck 2006: 22, 43, 93). But when a tense grammeme contains some feature(s) in addition to its tense (temporal) feature (past, present, etc.), e.g. (non-)boundedness as with the aorist-imperfect contrast in some languages, ${ }^{8}$ it is said to be of a mixed tense-aspect nature. This duality of meaning raises questions: how should such grammemes be differentiated from purely tense grammemes (preterite, present, future) ${ }^{9}$ In the case of the present perfect the problem is especially bothersome because of its elusive essence outside the temporal domain. There is a general consensus in linguistics on the "second nature" of the aorist-imperfect contrast: it is aspectual, the "first nature" being temporal. But what is the "second nature" of the present perfect?

The "second nature" of the English present perfect has been sought mainly in three directions. The first, according to which the perfect is an aspect together with the indefinite tenses and the progressive (standard in $20^{\text {th }}$ century grammars, see Quirk et al. 1980) is outdated. ${ }^{10}$ Today's understanding is that the progressive is an aspect, while the perfect and the indefinite tenses are not. The second direction for defining the present perfect has no name and covers its general meaning, most frequently understood as "current relevance" (Comrie 1985: 24ff; Bybee et al 1994: 61ff; Huddleston and Pullum 2002: 143ff; Downing and Locke 2002: $361 \mathrm{ff}$ ), but various other definitions and corresponding terms are also in use: resultativeness, indefinite past, embedded/continuative past, extended/expanded now, etc. (Lindstedt 1985: 96ff, McCoard 1978, Fenn 1987, McCawley 1988: 226, Elsness 1997: 67-68, Holton et al. 1997: 300ff, Musan 2002, Androutsopoulos 2002: 36, Aikhenvald 2004:112, Eul 2008: 99, 106). As Moens (1987: 94) rightly observes: "The descriptive accounts of the perfect are vague, they make unprincipled distinctions between different uses of the perfect, without explaining

\footnotetext{
${ }^{7}$ In the past, present, future or future-in-the-past. By a situation, any of the members in Vendler's (1957) classification (state, activity, accomplishment, achievement) is understood.

${ }^{8}$ Languages featuring an aorist-imperfect contrast are, e.g., Spanish, Greek, Bulgarian - these three belonging to different groups of the Indo-European family.

${ }^{9} \mathrm{Cf}$. Klein's (1994: 123) reasoning about the so-called present historical "tense".

${ }^{10}$ Issues related to the tendency for perfect forms to impart completion to Vendlerian states and activities are here disregarded. See the point formulated in Verkuyl (2008: 43): "the presence of the perfect auxiliary contributes substantially to the sense of completion together with the meaning of the Past participle".
} 
why the perfect should fulfil such an arbitrary looking collection of functions." The third direction for revealing the "second nature" of the present perfect is in the domain of modality, but this has usually been applied to languages other than English. Aikhenvald's (2004) extensive cross-language data shows that the perfect systematically manifests what the author calls non-firsthand (i.e., non-witnessed), a modal value. ${ }^{11}$ In this paper, the "second nature" of the English present perfect will be sought in this direction. In any case, the perfect - as an abstraction from the plusquamperfect, the present perfect, etc., is not a tense, hence the practice of calling it a tense ought to be abandoned.

\section{What is Tense?}

According to the understanding here, the main problem in this linguistic field is that grammatical categories and grammemes are, as a rule, characterized in terms of what is expressed by them, not in terms of what is not expressed, and this approach hampers the identification of the essence of certain grammemes. To start correcting the status quo, a different understanding of tense will now be proposed, according to which tense does not solely serve to locate situations in time. It also serves to deploy another two entities: the participants and the speaker. As a generalization (previously formulated in Kabakčiev 2017: 351ff),

tense is a vehicle for the deployment onto the time axis of: (i) situations; (ii) participants in situations; (iii) the speaker.

It can be exemplified by the following two sentences:

a. John repaired the car

b. John has repaired the car

In (4a), a sentence with an indefinite past form, the speaker is located in the past, and so are the situation and the participants John and the car. In (4b), a sentence with a present perfect, the situation is again located in the past, as in the definition of the present perfect as a past situation with current relevance, but the speaker and the participants are now located in the present. The difference is discussed in more detail below. As regards the thesis that the participants John and the car are located in the past in (4a), it also follows from certain tenets in compositional aspect theory, where the participants are temporal entities (Kabakčiev 2000; 2019), see again below.

Sentences straightforwardly demonstrating the deployment in time of participants are very rare. Here are two. Suppose you are driving a car. Another car, with a barking dog in it, overtakes you. Seconds later, while the other car is

\footnotetext{
${ }^{11}$ Cf. the following statements: "perfect in Scandinavian languages also has a distinct nonfirsthand nuance" (Aikhenvald 2004: 112); in La Paz Spanish the preterite is employed to refer to something witnessed (Aikhenvald 2004: 114).
} 
still in view, the dog is no longer seen and a passenger in your car makes the following observations, otherwise mundane:

a. A dog was barking in that car

b. There was a dog in that car

In (5a) the observer/speaker is reporting not what the dog is doing now but what the dog was doing a fraction of a second earlier, despite the high probability for the dog to be still barking. Sentence (5b) is even stranger. It reports the "past existence" of a dog in the car in front - implicating its non-existence now, a split second later.

Why do people say there was a dog in sentences such as (5b) instead of there is a dog? The dog is still in the car in front, and obviously, in our understanding of this world, it has not died or evaporated into thin air. Do people use a past tense here because the dog is no longer in their vision? ${ }^{12}$ If this is the case, it is in full support of the definition above: the indefinite past places the participant $a$ dog onto a past-time segment. Thus it also registers it in the brain as existing not in the present but in the past (see Kabakčiev 2000: 91ff). Furthermore, the indefinite past obviously places the speaker too (the passenger in the car) onto a past segment of the time axis. By saying There was a dog in that car, the speaker indicates s/he was on a past-time segment a split second before the dog disappeared from view. Meanwhile note that that car is also a participant in the situation, hence it is also deployed on a past-time segment, along with $a$ dog and the speaker. Thus, the meaning of (5b) must be taken to include a situation with a duration of some seconds and two participants in it, a dog and that car; each participant also having a duration of some seconds.

What is the conclusion to make from this analysis of (5)? It is that what is communicated by language reflects the speaker's experience of situations not as static pictures but together with the participants "in progress" - that is, the speaker's experience approximates $\boldsymbol{a}$ video (film/TV representation/moving picture), not a photograph/photographs of stationary objects (Kabakčiev 2000: 99$100,117-118)$. But despite this, the conviction of the receiver/hearer of (5b) and similar sentences is that the participants are stationary entities as in photographs, not moving as in videos. Read the sentence again: There was a dog in that car. What do we normally conceive of the participants a dog and that car? Do we interpret them as entities in motion, lasting several seconds and belonging to the past (before the dog disappears from view)? No. We normally think of them as physical objects stable in time, existing now as well as in the near or distant past, and we also project their existence into the future, i.e., we picture them mentally as in a photograph, not as in a video. But the careful analysis of the data suggests that in the brain they are registered otherwise, as if in a video (Kabakčiev 2000: 99100, 117-118; 2019).

\footnotetext{
${ }^{12} \mathrm{~A}$ preterite is used in many languages: There was a dog in that car (English), In diesem Auto war ein Hund (German), В этой машине была собака (Russian); В тази кола имаше куче

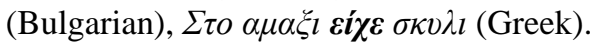


Obviously, the current and past presence of physical objects (their existence now and prior to a situation depicted) conceals the circumstance that in sentences such as (5a-b), products of the human brain, ${ }^{13}$ a dog and that car are not so much physical entities but pictures in the brain moving in space and time (Kabakčiev 2000: 99-100; 2019). The dog is stationary in the car but moving in space with the car, and, more importantly, in time. Summing up, in these two short "videos" in the speaker's brain (5a-b) a dog is an entity with some seconds of duration: a temporal entity in the mind of both speaker and hearer. It is a problem for cognitive theory why the human brain registers $a \operatorname{dog}$ in (5a-b) as a temporal entity but then subsumes it under the general notion of "dog" with its physical nature which is "permanent", not temporary/temporal. From a common-sense point of view, a dog is something physical. But in (5a-b) "the nature of a dog" is not physical, it is temporal. It is a moving picture with a short duration in the speaker's mind, and this moving picture is then transferred into the mind of the hearer. The hearer, too, obviously registers $a d o g$ as a temporal entity first and then subsumes it under the general notion of "dog" with its "physical nature". Put otherwise, the minds of both speaker and hearer hide the temporal nature of the participants from the "normal awareness" of speaker and hearer. ${ }^{14}$

It can easily be conjectured now that if speaker and hearer would have to register in language all situations permanently occurring around with all the participants in them as temporal entities, not subsumed under a physical structure, the memory of both speaker and hearer would soon clog and stop working (Kabakčiev 2000: 117ff; 2019: 211). It is also indicative that the illogicality in (5b) and the temporal feature (seconds of past existence) of the participants remain unnoticed or ignored by the native speaker. Asked "Why do we say things like There was a dog in that car instead of There is a dog in that car?", respondents admit that the former is, indeed, illogical - but it is "a specific way of saying things" as in hyperboles, metaphors and other figures of speech. People dismiss the illogicality of $(5 \mathrm{~b})$ because they are interested in the pragmatic impact of language, not in its structural organization.

But, more importantly, it remains beyond the attention of linguists that many other sentences in English and other languages manifest these and similar illogicalities. The illogicalities are again tense-aspect related, again remain unnoticed or ignored by the average speaker, and the temporal nature of participants is again concealed. This time, however, the sentences are not very rare. Cf. (6):
a. Iniesta passed a beautiful ball to Messi
b. Iniesta passed beautiful balls to Messi
c. The judge banged a gavel

For (6a) to be really and literally true, it ought to mean that there were several balls on the football pitch, Iniesta chose one, beautiful, and passed it to Messi. This

\footnotetext{
${ }^{13}$ All sentences are products of the human brain.

${ }^{14}$ But despite this concealment, the markers of temporal boundedness in a dog and that car remain - these are the article $a$ and the determiner that (Kabakčiev 2000, 2019).
} 
is a possible interpretation. But we know that it is not the typical one in our knowledge of the world. In the usual reading of (6a) there is only one ball on the pitch and Iniesta gives a pass to Messi, and what is especially important is that $a$ ball here does not refer to a beautiful physical object, it refers to a pass that is beautiful. Analogously, (6b) does not refer to physically beautiful balls, it refers to beautiful passes. Recall the argumentation above, according to which a dog in (5b) is a temporal entity with a short duration rather than one with a physical constitution. Here again, a beautiful ball and beautiful balls, that would normally have to be physical entities, are not physical but temporal. They are acts: a single one in a beautiful ball, non-bounded iterative ones in beautiful balls. The "illogicality" in (6a-b) is also present in (6c). It ought to mean that the judge had several gavels on the desk in front, grabbed one and banged the desk with it. But (6b) does not normally mean that. It means that the judge had only one gavel in front and gave a bang with it. Again, a gavel here does not refer so much to a physical object; it refers to a bang with a gavel. The "illogicality" is again unnoticed by the average speaker, as in the sentences with the dog and the beautiful ball(s), and shows that what appears in language is often not what is really meant.

\section{What Do the Grammemes Present Perfect and Past Indefinite "Mean"?}

Primarily discussed above was the indefinite past. But the aim of the paper is to analyze the present perfect. The essence of the perfect across languages is taken to be best represented by the present perfect - not by the future perfect or the plusquamperfect, and its definition usually hinges on the definition of the preterite in the relevant language. In the case of English, the present perfect is contrasted to the indefinite (simple) past. The former is usually described as "a past situation with current relevance", the latter as "a past situation with no connection to the present” (Bybee et al. 1994: 54, 61, Comrie 1985: 24-25, among others). A completely different conception is proposed here. According to it, the present perfect cannot be understood in terms of what it does, it can be understood in terms of what it does not do. Following the example of the aspectological analysis of the indefinite past, the idea that a grammeme can be understood in terms of what it does not do could even be seen as a methodological principle. The indefinite past cannot be understood aspectologically in terms of what it does; it can be understood in terms of what it does not do; cf. (6a-b) above, where the indefinite past does not and cannot express an aspect value. While passed in (6a) explicates perfectivity, in (6b) it explicates imperfectivity, in both cases through the compositional aspect mechanism (Verkuyl 1972, 1993, Kabakčiev 2000, 2019). Until the 1980s, it was universally accepted that the English indefinite past has "a second meaning", aspectual. English grammars tried very hard to define this meaning for decades and their attempts failed over and over again - but the descriptions of the indefinite past as "aspect" remain to the present day. The gross inability of English grammars to explain tense and aspect has just been meticulously demonstrated by Bulatović (2020). She analyzes ten English 
grammars that fail (some dramatically) to explain that the indefinite past grammeme has no aspectual meaning at all and that its definition ought to contain negative information, not positive. The definition ought to delineate what the past indefinite does not do, not what it does - because the indefinite past is an "empty bag" capable of accommodating any aspectual meaning arising in a sentence or context (Kabakčiev 2017: 238, 349, 387). ${ }^{15}$

\section{But What Are the Indefinite Past and the Present Perfect Not Then?}

It is common knowledge that aspectologically the English present perfect is largely identical (if not precisely) to the indefinite past (Androutsopoulos 2002: 36; Verkuyl 2008). It, too, is an "empty bag" that can accommodate any aspectual meaning in the sentence/context (Kabakčiev 2017: 203). But what is its "second nature"? What is its raison d'être? Following the conception of the indefinite past as an aspectological "empty bag", the idea to be launched here is that the essence of the present perfect is similarly related to what the perfect is not rather than to what it is. The raison d'être of the present perfect is to be sought in certain functional dependencies, not in "its meaning" - and through comparisons with the past indefinite again, but in a different manner.

The present perfect in Bulgarian, an Indo-European language similar to English in certain grammatical areas, notably tense, was shown above to serve an important function, "grammaticalizing" certain types of sentences. The sentences are incorrect with witnessed forms and correct with present perfect forms, the latter being non-witnessed. This grammaticalizing function is absent in English but it suggests that the present perfect might be a device to counterbalance the impact of certain grammatical entities in other languages as well - or even in all languages. In this vein, let us recall that prior to 1972 nobody in the linguistic world would dare propose that $(7 \mathrm{a}, \mathrm{b})$ and similar sentences are perfective. The "canon" in those times decreed that there is, simply, no such thing as perfectivity in English. Hence, it should not even be sought (Zandvoort 1962, Dušková 1983). Today, precisely conversely, thanks to the discovery of compositional aspect (Verkuyl 1972), there is not a shadow of a doubt that $(7 \mathrm{a}, \mathrm{b})$ are perfective sentences and $(7 \mathrm{c}, \mathrm{d})$ are imperfective:
a. Maria arrived
b. Maria read an article
c. Maria traveled
d. Maria read articles

Yet it must be heavily emphasized now that the perfectivity of $(7 \mathrm{a}, \mathrm{b})$ and the imperfectivity of (7c, d) are only default values (Kabakčiev 2000: 59, 82, 2019: $205 \mathrm{ff})$ - i.e., these are not values fixed on such sentences once and for all. If the

\footnotetext{
${ }^{15}$ Bulatović (2020) points to Declerck (2006) and Kabakčiev (2017) as "specialized English grammars" written by aspectologists and offering adequate descriptions of aspect in compositional terms.
} 
sentences in (7) are used independently or in contexts that do not contradict their default aspect values, they explicate them. But if embedded in sentences/contexts rejecting the default values, these sentences start signaling different aspectological values. Observe how, due to the addition of certain elements in (7) - some types of adverbials, some direct or prepositional objects, $(8 \mathrm{a}, \mathrm{b})$ explicate imperfectivity, and $(8 \mathrm{c}, \mathrm{d})$ perfectivity:
a. Maria arrived every day by train
b. Maria read an article for hours on end in those days
c. Maria traveled a large distance
d. Maria read articles about the Minoan civilization and was fascinated right away

Along these lines, an explanation of the meaning of the present perfect will be proposed, in which certain negative values are found in sentences with present perfect forms - such that cannot be discerned by viewing the present perfect as a past situation with current relevance or resultativeness, etc. Consider (9a-b) and follow the questions asked with respect to them - along with the answers:
a. The train arrived
b. The train has arrived

Let us first ask about (9a), a sentence with an indefinite past verb form: where are the participant, the situation and the speaker? Here is the answer.

(1) The participant (the train) is in the past;

(2) The situation referred to by the verb form (arrived) is in the past.

(3) The speaker is in the past.

Why is the participant the train in the past? Why is the speaker in the past? Recall (5a-b), where the participant the dog and the speaker are in the past. By using past tense forms the speaker deploys the participant the dog as well as himself/herself onto a past-time segment, despite the circumstance that the speaker's location in the past may be only a fraction of a second prior to making the utterance in (5a-b) or (9a). Analogously, the speaker in (9a) is deployed in the past by the indefinite past grammeme - and likewise the participant the train is also deployed in the past. As for the situation referred to by arrived, there can hardly be any doubt that it is located in the past - as per the understanding of the past as a grammatical device to locate situations in time.

Now let us ask where the participant, the situation and the speaker are in (9b), a sentence with a present perfect verb form. Here is the answer.

(1) The participant (the train) is in the present.

(2) The situation referred to by the verb form (has arrived) is in the past. ${ }^{16}$

(3) The speaker is in the present.

\footnotetext{
${ }^{16}$ But the situation also has a pragmatic relevance for the present.
} 
Why is the participant the train in the present? Why is the speaker in the present? It can be argued that in (9b) the semantics of concatenations such as the train + has involves a current, present status and location of the train, although the train may turn out to have been involved in other situations after the addition of the past participle to the sequence. In this case arrived adds an accomplishment (Vendlerian) to the current status of the train - in the present, but the accomplishment itself belongs to the past. There can hardly be any doubt that when we produce sentences such as The train has arrived, the train is in the present - unlike in The train arrived, where it is in the past. As for the speaker, in (9b) $\mathrm{s} / \mathrm{he}$ is in the present because s/he cannot be in the past and ascribe a present status to the train from the past - that is, for the future, for a point not yet reached by both the train and the speaker himself/herself. ${ }^{17}$ In other words, if we take it that in (9b) the speaker is somehow in the past, s/he would then have no way of knowing what the staus quo in the present is (including the status quo of the participants), because the present for the speaker would then actually be a future an unknown status quo.

The important conclusion is that if in (9b) the speaker is in the present but the arrival of the train is in the past, the speaker was not a witness to the situation ("the arrival of the train"), in line with what Aikhenvald (2004: 112) calls a "semantic link between a non-firsthand evidential and a perfect". It also fully stands to reason to assert that, had the speaker witnessed the arrival of the train, s/he would have used sentence (9a) instead. Obviously, the assertion that in (9b) the speaker is not a witness to the situation should be taken to be valid for most sentences like (9b) with present perfect verb forms, and this is the negative value predicted above to hold for the "second nature" of the present perfect: "nonwitnessing".

But why is the non-witnessed value of the present perfect hidden to the native speaker, and even to linguists? In all probability, the reason for this is the impossibility to contrast the English present perfect grammeme to a witnessed one, as such a grammeme is absent in English. In any case, if the assertion above about the present perfect is true, it must be re-formulated as a conclusion and a generalization.

The English present perfect is a non-witnessed verb form, though it does not directly signify (denotelencode) this value. It only signals/explicates it. And if the present perfect is a non-witnessed verb form, then the English indefinite past - per argumentum a contrario and per the understanding of the indefinite past as a past situation with no connection to the present, is, conversely, a witnessed verb form. But the English indefinite past is a witnessed verb form merely by default, i.e., when its value witnessed is not canceled within a sentence/context. Also, the indefinite past is not grammatically marked as witnessed; it signals this value, it does not signify (denotelencode) it.

The preliminarily expected conclusion that the essence of the English present perfect is to be identified in negative terms is thus reached. The present perfect

\footnotetext{
${ }^{17}$ Unless a future tense form is used, but it is not the case here.
} 
features the value non-witnessed - but does not signify it, it only signals it! Recall again the similar thesis, completely endorsed in linguistics today thanks to the compositional aspect theory, that English sentences with an indefinite past such as $(7 \mathrm{a}, \mathrm{b})$ and (9a) signal perfectivity, while sentences such as $(7 \mathrm{c}, \mathrm{d})$ signal imperfectivity, and that perfectivity and imperfectivity are signaled by default (Kabakčiev 2000: 59, 82; 2019: 205ff). Just like the present perfect, the indefinite past is described not in positive but in negative terms: it does not encode perfectivity or imperfectivity; it allows their signaling depending on the impact of sentences/contexts. But notice the difference that while the English indefinite past signals the value witnessed by default and can hence be coerced into signaling non-witnessed under the influence of a sentence/context, the present perfect is non-witnessed in itself, as the situation it portrays is located in the past but the participants and the speaker are in the present. Hence, the non-witnessed value of the present perfect can hardly be coerced into witnessed. One cannot have a witnessed situation in the past and simultaneously have the participants and the speaker in it deployed in the present, not in the past. This thesis is supported by the observation that sentences such as English (10a) or Bulgarian (10b) do not explicate a witnessed value, despite the use of $1^{\text {st }}$ pers.sg. forms strongly presupposing it:
a. I have visited Westminster Abbey
b. Az sam poseshtaval ${ }_{\text {PERF,NON-WITN,IMPFV }}$ Uestminstarskoto abatstvo $^{18}$
'I have visited Westminster Abbey'
c. I visited Westminster Abbey

Unlike English (10c), which easily explicates the value witnessed with the indefinite past, both (10a) and (10b) seem to somehow distance the speaker from his/her own experience of visiting Westminster Abbey. It is as if the speaker in $(10 \mathrm{a}, \mathrm{b})$ has entrusted somebody else with the description of his/her visit to Westminster Abbey.

If the value of a verb form is to be witnessed, it is natural for the speaker, the situation and the participants to be at the same time-axis location. Compare Bulgarian (11a), with the witnessed forms vidya 'saw' and pristigna 'arrived' and the value witnessed grammatically encoded, to its English correspondence (11b), where saw and arrived only signal the value witnessed - through the general meaning of the sentence:
a. Petar vidya ${ }_{\text {wIN }}$, che Maria pristigna ${ }_{\text {wIT }}$
'Peter saw that Maria arrived'
b. Peter saw that Maria arrived

There can be no doubt that for the value witnessed to be directly signified, as in Bulgarian, or signaled, as in English, the speaker, the situation and the

\footnotetext{
${ }^{18}$ There is a problem here: the present perfect tends to imperfectivize the situation in $(10 \mathrm{a}, \mathrm{b})-$ in both languages (Bulgarian and English). It will not be dealt with, for lack of space. Cf. the opposite phenomenon in Footnote 10.
} 
participants must be at the same time-axis location in the past. Among other things, this means that it would be wrong to assert that the English present perfect is non-witnessed by default, because a default value is such that can be turned/coerced into an opposite one by the impact of some additional element(s) in the sentence/context, cf. The train arrived, perfective, vs The train always arrived, imperfective. It can be argued that the present perfect (The train has arrived) is "ultimately non-witnessed" and non-coercible into a witnessed value, just like The train always arrived is an ultimately imperfectivized expression, non-coercible into a perfective one by the addition of perfectivizing elements.

For some linguists, the definition of the indefinite past as witnessed by default and of the present perfect as non-witnessed in itself might sound strange and astonishing. Let us recall again that prior to 1972 nobody in the linguistic world would describe an English sentence such as (9a) as perfective, and nobody would describe (12b, c), (13a-b) as imperfective:

(12) a. The tourist visited the castle

b. The tourist visited castles

c. Tourists visited the castle

(13) a. The tourist hated the castle

b. Trains arrived

Conversely, today a serious linguist would not cast any doubt on the perfectivity of (12a) and the imperfectivity of (12b,c) and (13a-b). Of course, things are more complicated than in those explanations given in grammars and other linguistic publications, according to which the relevant aspectual readings in (12) and (13) must be sought in the indefinite past. No, it is not the indefinite past that triggers the perfective reading of $(12 \mathrm{a})$ and it is not the indefinite past that triggers the imperfective readings of $(12 b, c)$ and $(13 a-b)$. The indefinite past has a role to play in the effectuation of these two readings, but this is a different kind of role. The indefinite past allows these two opposite readings, the perfective and the imperfective one, depending on the impact of the elements in the rest of the sentence/context.

Now that the indefinite past is defined as a witnessed form by default, and the present perfect as a non-witnessed form in itself, this conception bears similarity to that of the indefinite past as an "empty bag" capable of accommodating any aspectual value arising in a sentence or context. The default witnessed value of the indefinite past depends on the absence of certain elements in the sentence. See (9ab) above and compare with (14a-f):

(14) a. I saw that the train arrived

b. Peter said that the train arrived

c. According to $\mathrm{CNN}$, the train arrived

d. Vidyah ${ }_{\text {wTIN }}$, che vlakat pristigna ${ }_{\text {wTIN }}$

'I saw that the train arrived'

e. *Petar kaza ${ }_{\text {wTIN }}$, che vlakat pristigna ${ }_{\text {wIT }}$

'Peter said that the train arrived'

f. Petar kaza ${ }_{\text {WITN }}$, che vlakat e pristignal ${ }_{\text {PERFECT }}$

(lit.) 'Peter said that the train has arrived' 
First, there is no doubt that an indefinite past tense form such as the train arrived can, in principle, manifest a witnessed value: in simple isolated sentences such as (9a) and in complex sentences such as (14a) - where the context (in the latter case the previous verb) allows, supports or requires the signaling of witnessed. Elsewhere, not in isolated sentences such as (9a), it can signal nonwitnessed too, due to the impact of other elements in the sentence/context. In $(14 \mathrm{~b}, \mathrm{c})$ the values non-witnessed and cancelable in the train arrived are generated by the impact of the verb said and the adverbial according to. In any case, the absence of a witnessed grammeme in English does not hamper sentences, clauses or expressions containing an indefinite past tense form to signal that the speaker witnessed the situation. Note, however, that although English (14a) and Bulgarian (14d) appear fully corresponding, semantically equivalent, the witnessed value of Bulgarian vlakat pristigna 'the train arrived' is grammatically encoded and hence fixed, while in English the train arrived is witnessed only by default and hence coercible into non-witnessed. The essence of this difference emerges when comparing the grammaticality of English (14b) with the non-grammaticality of Bulgarian (14e). At first sight the sentences are identical. However, English (14b) is correct because the phrase the train arrived is not grammatically witnessed in isolation. It is witnessed by default, hence can be coerced into non-witnessed, as in $(14 b, c)$. Conversely, Bulgarian $(14 \mathrm{e})$ is non-grammatical because the value witnessed in vlakat pristigna 'the train arrived' is grammatically encoded, noncancelable and non-coercible into non-witnessed or cancelable - while the preceding main clause Petar kaza 'Peter said' uncompromisingly requires the presence of the values non-witnessed and cancelable in the following phrase. The result: (14e) with the witnessed pristigna 'arrived' is non-grammatical, and the present perfect in (14f) - being a non-witnessed and cancelable form, is used to "grammaticalize" (14e).

Second, (9a), The train arrived, with an indefinite past form, can also manifest the value non-witnessed (interpreted as renarrated or inferrential, etc.), but for this to happen it must be embedded in sentences such as $(14 \mathrm{~b}, \mathrm{c})$. The non-witnessed value of the train arrived in $(14 \mathrm{~b}, \mathrm{c})$ is generated by the preceding phrases Peter said that and according to $C N N$ - which require the subsequent use of cancelablecontent expressions (and the value cancelable is subsumed under non-witnessed). But if (9a) is an isolated sentence whose meaning is not influenced by neighboring sentences, its reading would rather, as a rule, be such that the speaker will be taken to have witnessed the situation - and its content will normally be read as noncancelable. This thesis about non-cancelable was proposed in Kabakčiev (2018: 248ff), where similar isolated sentences (15a-b) were taken to manifest noncancelable content:
a. John is drinking beer
b. John was drinking beer 
-However, embedded in semantico-syntactic schemata containing expressions such as $X$ said that and according to, requiring cancelable content in the subsequent phrase/clause, these sentences start to signal cancelable content.

Why do expressions such as $X$ said that and according to generate cancelable content in the rest of the sentence? It is because they open two opposite possibilities: for the proposition in the rest of the sentence to be either true or not true, for the situation in it to be either happening or not happening, etc. (Kabakčiev 2018). See the phrase the train arrived in $(14 \mathrm{~b}, \mathrm{c})$, where it is implicated that the train may have arrived or not - because of the impact of the preceding expressions $X$ said that and according to, which require cancelable content in the rest of the sentence.

As already established, sentences such as (9a) above can be taken to manifest the feature witnessed by default, unless embedded in a semantico-syntactic schema containing $X$ said that or according to, etc. It is now worth asking whether the value witnessed is necessary in language at all, drawing parallels with languages where it is grammatically represented. In Kabakčiev (2018) it is argued that the English SOT phenomenon, incorrectly termed "a rule" due to a misunderstanding of its nature, is actually a mood whose function is to prevent the loss of non-cancelable content. Just like the Bulgarian present perfect "grammaticalizes" sentences such as (1) turning them into (2), the English backshift mood "grammaticalizes" (16), containing present perfect forms, by turning them into (17), with plusquamperfect forms:
a. *I saw that the train has arrived at the station
b. *John said that the train has arrived at the station
a. I saw that the train had arrived at the station
b. John said that the train had arrived at the station

Why should this grammaticalization be effected? In order to eliminate the danger of losing the feature non-cancelable in sentences such as (9b) when they are in isolation (see Kabakčiev 2018). In any case, (17) shows the grammaticalizing effect of the English past perfect, strongly supporting the argument that the perfect is a necessary grammeme. However, it is necessary not because of its "meaning" but because of the structural functions it performs.

\section{Exactly "How Witnessed" Is the Bulgarian Witnessed Form?}

The concept of witnessing, found in certain grammatical entities in certain languages, as well as in English as a semantic feature, is, however, complex and controversial. Bulgarian is a language in which the equivocacy of witnessed forms can easily be demonstrated. The standard definition of witnessed contains the assertion that a speaker using this form has personally witnessed the situation described - mainly through his/her vision and/or hearing, perhaps also through the other- senses. But there is a serious problem here. In an attempt to report normally what happened, the speaker cannot, in many cases, use another verb form in Bulgarian, non-witnessed, e.g., a renarrative or an inferrential. Because if the speaker does this, additional implications arise - running contrary either to what 
objectively happened or to what the speaker intends to communicate. This occurs, for example, with historical events that did take place but were not personally witnessed - not seen on TV, not heard on the radio. Furthermore, a TV or a radio may report something that was not witnessed by them. To give an example, the historical event in (18a) below could be reported by a radio station on the basis of information from another radio station - which means that it is renarrated. Yet the verb form in (18a) is witnessed, not renarrative, but despite this it is correctly used.

In 1968, I myself knew that Czechoslovakia was invaded by the Warsaw Pact, but I never personally witnessed this. What radios and TVs in my country reported was "brotherly help administered to our Czechoslovak comrades". I knew, of course, that Czechoslovakia was invaded, not helped (told in the family). All this means that, following the definition of the witnessed grammeme requiring the speaker to have personally witnessed what s/he reports, after the 1968 invasion I ought to use not (18a), with a witnessed form, but $(18 \mathrm{~b}, \mathrm{c})$ - with a renarrative or a perfect:
a. Armii na varshavskiya pakt navlyazoha $\mathrm{wITN}_{\mathrm{v}} \mathrm{V}$ Chehoslovakia
'Warsaw Pact armies invaded Czechoslovakia'
b. Armii na varshavskiya pakt navlezli RENARR $\mathrm{V}$ Chehoslovakia
'Warsaw Pact armies invaded Czechoslovakia'
c. Armii na varshavskiya pakt sa navlezli PERFECT $\mathrm{V}$ Chehoslovakia
'Warsaw Pact armies have invaded Czechoslovakia'

But there is a problem. If I were to use a renarrative as in (18b), this would trigger an implication that the assertion may be untruthful - because of the uncertainty of all information supplied by third parties (Kabakčiev 2018). If I were to use a present perfect as in (18c), this would imply that I am making an inference - and an inference is dubitable by itself (an inference is either true or not). To sum up, the use of $(18 \mathrm{~b}, \mathrm{c})$ would cast a doubt on the truthfulness of the information, and this would contradict the fact that I simply knew, whatever my source, that the Warsaw Pact had invaded Czechoslovakia. Hence, renarrative or present perfect forms would be out of place here - for being non-witnessed, renarrative and/or inferrential, hence dubitable. What verb form to use then? Only the witnessed one in (18a) remains, despite the fact that I did not witness the 1968 invasion.

Thus, despite the standard definition of witnessed, sentences in Bulgarian containing witnessed forms do not always meet the requirement for the speaker to have witnessed the situation. To provide other examples in support of this thesis, if asked why the roof of my house is damaged I can answer that a storm hit it, using a witnessed form - though I was absent during the storm (never saw or heard it). Or if a neighbor asks where my children are, I can reply that my wife took them to a concert, using a witnessed form, although I did not see or hear my wife take them to a concert (but I know she did):

\footnotetext{
a. Prolivna dazhdovna burya udari ${ }_{\text {wITN }}$ kashtata mi

'A torrential rainstorm hit my house'

b. Zhena mi zavede ${ }_{\text {wIT }}$ detsata na kontsert

'My wife took the children to a concert'
} 
The two alternative forms (renarrative and perfect) that could, in principle, be used here instead of the witnessed ones in $(19 a-b)$, would damage the intent of $(19 \mathrm{a}-\mathrm{b})$ :

\begin{tabular}{|c|c|c|}
\hline (20) & a. & $\begin{array}{l}\text { Prolivna dazhdovna burya udarila } \\
\text { 'A torrential rainstorm hit my house' }\end{array}$ \\
\hline & b. & $\begin{array}{l}\text { Zhena mi zavela } \text { RENARR }_{\text {detsata na kontsert }} \\
\text { 'My wife took the children to a concert' }\end{array}$ \\
\hline (21) & a. & $\begin{array}{l}\text { Prolivna dazhdovna burya e udarila } a_{\text {PERFECT }} \text { kashtata mi } \\
\text { 'A torrential rainstorm hit my house' }\end{array}$ \\
\hline & b. & $\begin{array}{l}\text { Zhena mi e zavela } \\
\text { 'MyRFECT detsata na kontsert } \\
\text { 'My took the children to a concert' }\end{array}$ \\
\hline
\end{tabular}

If I answer a question why my roof is damaged using (20a) with a renarrative, this would mean that I emphasize the fact that I was told that a rainstorm hit the house. This is not the case. I simply know that a rainstorm hit my house, whatever my source. If I use (21a) as an answer, with a present perfect, this would mean that I am either re-narrating or making an inference, and an inference is by virtue of its nature non-witnessed and dubitable. This is again not the case. I simply know that a rainstorm hit my house. Similarly, if I answer the neighbor's question about my children using (20b) or (21b), I will be saying that I was told that my wife took the children to a concert (20b) or that I am making an inference that my wife took the children to a concert (21b). Not true in both cases. I simply know that my wife took the children to a concert, despite the fact that I did not witness the act. ${ }^{19}$ The definition of witnessed in Bulgarian is not a convincing one and is in need of serious revision.

The reasoning here appears to be mainly valid for Bulgarian and similar languages featuring a witnessed grammeme, on the one hand. But, on the other, it can be argued that the value witnessed, with its fuzzy nature, can be successfully applied to languages like English, and in particular to the indefinite past grammeme. It is high time for the world community of anglicists to challenge the idea that the English present perfect is something that encodes current relevance or resultativeness, discard these and similar mysterious notions and mantras and consider the proposal that the indefinite past is witnessed by default - and that the present perfect is a non-witnessed form by itself, respectively.

\section{Is it Necessary to Signify or Signal the Value Witnessed in Language?}

The fact that many (probably most) languages do not feature a witnessed grammeme, yet there are languages that do, raises questions. Why are there such languages? Must the feature witnessed (grammaticalized or not) be looked for in a language? English grammars have never discussed the possibility for English to

\footnotetext{
${ }^{19}$ I know that my wife has taken the children to a concert today, 15 July, because I bought the tickets a month ago, on June 15, and I remembered the date of the concert, 15 July.
} 
signify or signal witnessed. ${ }^{20}$ As already argued, prior to Verkuyl's discovery of compositional aspect, perfectivity was thought to be absent in English, but today it is universally recognized as present - and important. Nowadays it is witnessed that is taken to be non-existent. But is it really absent and not worth looking for? Let us consider some sentences, (22a-c), in another language without a witnessed grammeme, Russian:
a. Poezd pribyl
'The train arrived/has arrived'
b. Ya uvidel, shto poezd pribyl
'I saw that the train arrived'
c. Kto-to skazal, shto poezd pribyl
'Somebody said that the train arrived'
d. I saw that the train arrived at the station
e. Someobody said that the train arrived at the station

Despite the absence in Russian of a distinction between preterite and present perfect (Russian has only three tense verb forms - preterite, present, future) and between witnessed and non-witnessed forms, Russian (22a) manifests two separate meanings: one corresponding to the dependent clause in (22b), witnessed, and another one corresponding to the dependent clause in (22c), non-witnessed. Witnessed in (22b) and non-witnessed in (22c) are values generated by the semantics of the main clause: (22b) triggers witnessed in poezd pribyl 'the train arrived' by the main clause ya uvidel 'I saw'; (22c) triggers non-witnessed by the main clause kto-to skazal 'somebody said', the latter requiring a non-witnessed form with cancelable content in the dependent clause. If English is used as a comparison, Russian (22a) will have a meaning corresponding to English (9a) above, witnessed by default, or to (22d), witnessed due to the previous phrase ( $I$ $s a w)$, and another one corresponding to English (9b), non-witnessed because of the non-witnessed nature of the English present perfect, or to (22e), non-witnessed because of the impact of somebody said. If Bulgarian, featuring a grammatically witnessed preterite and a non-witnessed present perfect, is used as a comparison, Russian (22a) will again have two separate correspondences: (23a), with a witnessed and non-cancelable verb form, and (23b), with a present perfect form, which is non-witnessed (renarrated and/or inferrential) and with cancelable content. Note that while Russian (22a) appears to have a unified meaning at first sight, its two correspondences in Bulgarian (23a-b) manifest completely different meanings - as do the English translations:

a. Vlakat pristigna ${ }_{\text {wTIN }}$

'The train arrived'

b. Vlakat e pristignal ${ }_{\text {PEREECT }}$

'The train has arrived'

\footnotetext{
${ }^{20}$ To the author's knowledge.
} 
This comparative-contrastive analysis indicates that: (i) the features witnessed and non-witnessed can be present (Bulgarian) or absent (English, Russian) as grammemes in a language; (ii) the present perfect grammeme can be present (English, Bulgarian) or absent in a language (Russian). The absence of this grammeme in a language does not hamper its meaning (semantic content) to be supplied in semantico-syntactic terms. But its presence in another language suggests that, as its meaning can also be supplied there in semantico-syntactic terms, it may in fact not exercise the functions it appears to exercise at first sight. Phrased differently, a grammeme may be thought to exercise some function(s) while actually it exercises some completely different function(s) - and in the case of the Bulgarian witnessed forms they may turn out to exist not in order to denote witnessed content but to exercise some other function(s), unexpected.

This has already been proved for articles. Languages without articles such as Russian and the majority of Slavic tongues show that the definite and the indefinite article are not at all necessary for signaling definiteness and indefiniteness, and the regular pattern of a definite and an indefinite article in English and other Germanic languages actually serves the explication of perfectivity, the explication of imperfectivity being performed by the zero article (Kabakčiev 1984, 2000, 2019). Thus the major function of the articles (definite and indefinite), their raison d'être, is not the signaling of definiteness and indefiniteness but is the signaling of temporal boundedness of nominal referents (Kabakčiev 2000, 2019). This means that the signaling of definiteness and indefiniteness is a residual function of the articles, not the major one. Analogously, given that there are languages without a present perfect grammeme and without perfects in general, given that current relevance and similar definitions of the present perfect are defective, given that the meaning of the present perfect must be defined in negative terms - all this suggests that the present perfect and the perfect exercise functions that have nothing to do with the meanings (such as current relevance) standardly ascribed to them.

The thesis that the present perfect exercises a function that has nothing to do with the meanings ascribed to it by the majority of researchers is supported, and actually proved, by its "grammaticalizing function" in Bulgarian and Montenegrin. The present perfect in English does not exercise this function but the perfect there could still be a device counterbalancing the impact of other grammatical entities. This idea is supported by the grammaticalizing function of the plusquamperfect in (17) above. The case with aspect and the regular pattern of the definite and the indefinite article is similar. Wherever aspect is a grammatical category, as in the Slavic languages, its raison d'être is to denote perfectivity/imperfectivity (temporal boundedness/non-boundedness). When temporal boundedness disappears in verbs, as happened in the history of the Germanic languages, articles emerge (Leiss 2000) - to encode temporal boundedness in nominal referents (Kabakčiev 1984, 2000: 153ff, 2019). As Abraham and Leiss (2012: 326) put it, "languages develop either a category of aspect or an article system". ${ }^{21}$ Hence, in simplified terms, the

\footnotetext{
${ }^{21}$ In some languages, e.g. Finnish, temporal boundedness in nouns is grammatically encoded not through articles but through the case system (Kabakčiev 2000: 157).
} 
answer to the question "Why do languages not have aspect in the verbs?" is "Because they have articles". And the answer to the question "Why do languages not have articles?" is "Because they have aspect in the verbs".

But there is an essential difference in the meanings encoded by aspect and articles. While aspect, i.e., the expression or signaling of temporal (non)boundedness, is pragmatically extremely important and hence necessary for every language, definiteness and indefiniteness explicated by the two articles can be defined as residual values. In other words, the ultimate task of both aspect in verbs and articles in NPs is the expression or signaling of aspect, i.e., temporal (non)boundedness, something important for human communication, but what is usually called expression of definiteness/indefiniteness by articles is a secondary function which is, first, not essential, second, it is easily performed by other means in languages without articles. Languages with no articles function flawlessly. No need is felt in them to encode grammatically definiteness and indefiniteness. When a noun is indefinite, this means (in simplified terms) that it appears for the first time in the context. When a noun is definite, this means that it is already introduced in the context - or is in some other way familiar to both speaker and hearer. Why should languages develop definite and indefinite articles then? The answer: because they need to signal aspect, not because they need to mark definiteness and indefiniteness (Kabakčiev 1984, 2000, 2019). A similar grammatical category that exists not to encode what it appears to encode - and the misrepresentation here is absolutely obvious - is gender. The raison d'être of grammatical gender is not to "mark gender" on nouns standing for people and animals. Gender is a device to facilitate reference to all nominals (not only people and animals) by breaking them down into groups (usually three, masculine, feminine, neuter) and thus ensure exact reference back to them through separate pronouns. In other words, articles and gender are categories exercising residual functions - i.e., these are not grammatical entities whose raison d'être is to denote what they seem to denote. They perform other tasks, functional, of importance for the internal mechanisms of language structure.

\section{Conclusion}

The present perfect is a grammeme that does not possess "own semantics" indispensable, necessary to be explicated or expressed. It exercises so-called residual functions similar to those of gender and the articles. ${ }^{22}$ Put otherwise, when a present perfect exists in a language, it is not there to express current relevance, resultativeness or similar queer notions. If the encoding of such notions were necessary and essential for human communication, all languages would feature present perfect grammemes. The fact is that there are hundreds of languages without a present perfect or a perfect in general - and their speakers understand each other perfectly. On the basis of the finding that the present perfect

\footnotetext{
${ }^{22}$ This conclusion ought to be generally valid also for the perfect (as an abstraction from the present perfect, the plusquamperfect, etc.), but no such claim is made here - for lack of space for the necessary analysis.
} 
in two languages, Bulgarian and Montenegrin, serves to counterbalance the effect of witnessed verb forms and thus "grammaticalize" certain sentences, and on the basis of the understanding of the present perfect in negative terms, the conclusion is that the raison d'être of the English present perfect is similar to the present perfect in Bulgarian and Montenegrin. By signaling the value non-witnessed (not by default), the English present perfect counterbalances the value witnessed present by default in the indefinite past grammeme. Of course, the present perfect grammeme in English and in cross-language terms is an extremely intricate phenomenon that may turn out to exercise other functions as well, in addition to the ones described here. ${ }^{23}$

This relatively short paper with an analysis focused on a single language, English, cannot claim to have identified the raison d'être of the present perfect in universal terms, for all languages. But, on the other hand, it offers clues for a possible future accomplishment of this task - that have not been previously discussed. If the raison d'être of the present perfect is similar in three languages, Bulgarian, Montenegrin and English, future research might show this to be the case for other languages as well - or even for all.

\section{Acknowledgements}

I thank the reviewers and editors for their comments and suggestions. I am also grateful to my wife for her judgements as a native speaker and for a warning she made at home one day: "Be careful not to use a red toothbrush - red toothbrushes are mine!" This helped me realize better the importance a negative value can have not only in language, as described in the paper, but also in everyday life: I have to remember not the many possible colors of my toothbrush but only that it will never be red, something much easier. Similarly, the use of a present perfect is automatically, beyond the speaker's awareness, interpreted as referring to a non-witnessed situation, i.e., one with a negative value.

\footnotetext{
${ }^{23}$ An anonymous reviewer does not quite approve of the idea that "all languages should be considered equal in terms of the use of the present perfect" - because "this tense is inexistent in some languages". My position, supported by the data from Bulgarian, Montenegrin and partly English, is that when this grammeme exists, it is not because its "semantics" is necessary but because it counters the impact of some other grammatical category/categories. The analysis shows that the present perfect has no own semantics necessary for communication. If it had, all natural languages would feature a present perfect, and the fact that many do not provides sufficient grounds for seeking the raison d'être of the present perfect in the domain of internal grammatical organization.
} 


\section{References}

Abraham W, Leiss E (2012) The case differential: syntagmatic versus paradigmatic case - its status in synchrony and diachrony. Transactions of the Philological Society 110(3): 316-341.

Aikhenvald A (2004) Evidentiality. Oxford: Oxford University Press.

Aikhenvald A (2008) Semi-direct speech: Manambu and beyond. Language Sciences 30: $383-422$.

Androutsopoulos I (2002). Exploring Time, Tense and Aspect in Natural Language Database Interfaces. Amsterdam/Philadelphia: John Benjamins.

Bulatović V (2013) Modern theories of aspect and Serbian EL2 learners. Belgrade English Language \& Literature Studies V: 65-79.

Bulatović V (2018) Negramatičnost aorista u izričnim rečenicama u crnogorskom (Non-grammaticality of aorist in reporting dependent clauses in Montenegrin). Lingua Montenegrina XI/2, 22: 3-13.

Bulatović V (2020) Thinking for speaking in the right aspect - on whether modern English grammars can do more. Revista Española de Lingüística Aplicada / Spanish Journal of Applied Linguistics. [forthcoming].

Bybee et al. (1994) Bybee J, Perkins R, Pagliuca W. The Evolution of Grammar. Tense, Aspect, and Modality in the Languages of the World. Chicago and London: The University of Chicago Press.

Chomsky N (1957) Syntactic Structures. The Hague: Mouton.

Comrie B (1985) Tense. Cambridge: Cambridge University Press.

Dahl Ö (1985) Tense and Aspect Systems. Oxford: Blackwell.

Declerck R (2006) The Grammar of the English Verb Phrase. Volume 1: the grammar of the English tense system. Berlin/New York: Mouton de Gryuter.

Downing A, Locke F (2002) English Grammar: a university course. London/New York: Routledge.

Dušková L (1983) Has the English verb system the category of aspect? Philologica pragensia 1 : 14-23.

Elsness J (1997) The Perfect and the Preterite in Contemporary and Earlier English. Berlin/New York: Mouton de Gruyter.

Eul A (2008) Tense, Aspect, Aktionsart and Related Areas Approaches to Analysing the Core Meaning of English Perfect Verb Forms. PhD Dissertation. KoblenzLandau University.

Fenn P (1987) A Semantic and Pragmatic Examination of the English perfect. Tübingen: Gunter Narr Verlag.

Grice HP (1975/1989) Logic and conversation. In Cole P, Morgan J (eds.), Syntax and Semantics III: Speech Acts: 41-58. New York: Academic Press.

Higginbotham J (2009) Tense, Aspect, and Indexicality. Oxford: Oxford University Press.

Holton D, Mackridge P, Philippaki-Warburton I (1997) Greek. A Comprehensive Grammar. London/New York: Routledge.

Huddleston R, Pullum G (2002) The Cambridge Grammar of the English Language. Cambridge: Cambridge University Press.

Kabakčiev K (1984) The article and the aorist/imperfect distinction in Bulgarian: an analysis based on cross-language "aspect" parallelisms. Linguistics 22: 643-672.

Kabakčiev K (2000) Aspect in English: a "common-sense" view of the interplay between verbal and nominal referents. Dordrecht: Kluwer. 
Kabakčiev K (2017) An English Grammar: main stumbling blocks for Bulgarians learning English. Stuttgart: Mariana Kabakchiev Verlag.

Kabakčiev K (2018) On non-grammaticality, "speaker ghosting", and the raison d'être of English sequence of tenses (SOT). Athens Journal of Philology 5(3): 221-253.

Kabakčiev K (2019) On the history of compositional aspect: vicissitudes, issues, prospects. Athens Journal of Philology 6(3): 201-224.

Klein W (1992) The Present perfect puzzle. Language 68: 525-551.

Klein W (1994) Time in Language. London/New York: Routledge.

Leiss E (2000) Artikel und Aspekt. Die grammatischen Muster von Definitheit [Article and aspect. The grammatical patterns of definiteness]. Berlin: de Gruyter.

Lindstedt J (1985) On the Semantics of Tense and Aspect in Bulgarian. Helsinki: Helsinki University Press.

McCawley JD (1988) The Syntactic Phenomena of English. Chicago/London: The University of Chicago Press.

McCoard R (1978) The English Perfect: tense-choice and pragmatic inferences. Amsterdam: North-Holland.

Moens M (1987) Tense, Aspect and Temporal Reference. PhD dissertation, University of Edinburgh.

Musan R (2002) The German Perfect: its semantic composition and its interactions with temporal adverbials. Dordrecht: Kluwer.

Pancheva R, von Stechow A (2004) On the present perfect puzzle. Moulton K, Wolf M (eds). Proceedings of NELS 34: 469- 484.

Quirk R et al (1980) A Grammar of Contemporary English. London: Longman.

Spronck S, Nikitina T (2019) Reported speech forms a dedicated syntactic domain. Linguistic Typology 23(1): 119-159.

Vendler Z (1957) Verbs and times. The Philosophical Review 66: 143-160.

Verkuyl H (1972) On the Compositional Nature of the Aspects. Dordrecht: Reidel.

Verkuyl H (1993) A Theory of Aspectuality. The Interaction between Temporal and Atemporal Structure. Cambridge: Cambridge University Press.

Verkuyl H (2008) Binary Tense. Stanford, CSLI Publications.

Zandvoort RW (1962) Is "aspect" an English verbal category? In Behre F (ed.). Contributions to English Syntax and Philology (Gothenburg Studies in English 14). Acta Unversitatis Gothoburgensis. Gothenburg. 